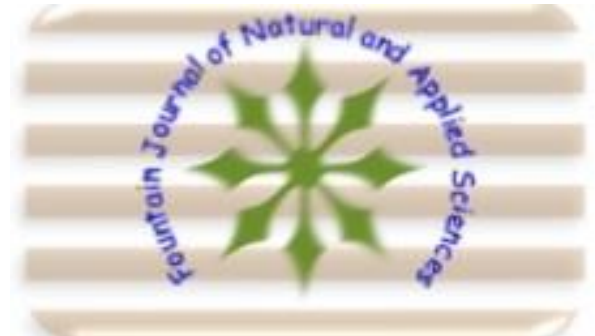

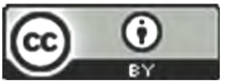

This work is licensed under Creative Commons Attribution 4.0 International License

DOI: 10.53704/fujnas.v5i1.88

A publication of College of Natural and Applied Sciences, Fountain University, Osogbo, Nigeria.

Journal homepage: www. fountainjournals.com

ISSN: 2354-337X (Online), 2350-1863 (Print)

\title{
Fabrication of dye-sensitized solar cells using anthocyanidins from the extracts of Roselle (Hibiscus sabdariffa)
}

\author{
${ }^{* 1}$ Abdulsalami, I. O., ${ }^{2}$ Banjo, S., ${ }^{2}$ Bello, I. A., O., ${ }^{3}$ Bolarinwa, H. S. and ${ }^{4}$ Egunjobi, I. A. \\ ${ }^{1}$ Department of Chemical Sciences, Fountain University, Osogbo, Nigeria. \\ ${ }^{2}$ Department of Pure \& Applied Chemistry, Ladoke Akintola University of Technology, Ogbomoso, Nigeria. \\ ${ }^{3}$ Department of Physics, Electronics and Earth Sciences, Fountain University, Osogbo, Nigeria. \\ ${ }^{4}$ Department of Science Laboratory Technology, Moshood Abiola Polytechnic, Abeokuta, Nigeria
}

\begin{abstract}
This study extracted, purified and applied the extracts of $H$. sabdariffa as photo-sensitizers in dyesensitized solar cells. The chemical properties of the extracts were examined using UV, FT-IR and GCFID spectroscopic studies. The photoelectrochemical properties of the extracts were also reported. U$V$ spectra showed significant difference in the absorbance and wavelengths of the crude and purified samples of H. sabdariffa (HSE and HSP respectively). The former has characteristic absorptions of 1.096 at $330 \mathrm{~nm}$ and 0.211 at $540 \mathrm{~nm}$, and the latter, 0.211 at $335 \mathrm{~nm}$ and 0.334 at $540 \mathrm{~nm}$. Shifts in the wavelengths of the absorption (around $330-350 \mathrm{~nm}$ ) and a characteristic decrease in the absorption between the HSE and HSP were observed. The FT-IR spectra of the HSE and HSP have similar characteristic absorbances peculiar to $\mathrm{OH}, \mathrm{C}=\mathrm{O}, \mathrm{C}-\mathrm{C}$ double bond (both aliphatic and aromatic) and $\mathrm{C}-\mathrm{O}$ HSP has two additional absorbances at $2365 \mathrm{~cm}^{-1}$ and $2075 \mathrm{~cm}^{-1}$. The spectra of the purified sample have bathochromic (red) shifts on the hydroxyl group and hypsochromic (blue) shifts on the benzene. The GCFID chromatograms revealed the presence of six anthocyanidins and the spectra data showed the amount of the anthocyanidins in $\mathrm{mg}$ per $100 \mathrm{~g}$ of the sample. The results showed that delphinidin was in abundance, followed by cyanidin in both samples. The quantities of the delphinidin increased with purity of the samples, while the others decreased with purity for both samples. The photovoltaic performances of HSE and HSP have the fill factors of 0.254 and 0.347 and the overall efficiencies of $0.118 \%$ and $0.645 \%$ respectively. From these data, the purified sample has higher fill factor and efficiency than the unpurified extract.
\end{abstract}

Keywords: Anthocyanins, dye-sensitized, solar cell, extracts, fill factor, efficiency.

\section{Introduction}

The redox and optical properties of natural pigments (like anthocyanins) make them well suited for a variety of applications (Simmonds, 2003; Qin
\& Clark, 2007). Anthocyanins from Hibiscus

*Corresponding author: +2348054284452

Email address: aiboldkip@gmail.com 
sabdariffa $(H$. sabdariffa) have been shown to have high antioxidant activity (Fossen et al., 2004; Ajiboye et al., 2011), indicating a relatively low oxidation potential (Harborne \& Williams, 2000; Kim et al., 2003). Anthocyanins are water-soluble glycosides of polyhydroxyl and polymethoxyl derivatives of 2-phenylbenzopyrylium or flavylium salts and an anthocyanin without sugar moiety is referred to as an anthocyanidin (Jordheim et al., 2006). Anthocyanins and anthocyanidins have been widely applied in various fields such as sensitizers in dye-sensitized solar cells (DSSCs).

Many research works have examined the anthocyanins in parts of plants - leaves, flowers, seeds, and others qualitatively (Boyo et al., 2013). This study concentrated on the quantitative analysis of the constituents of the extracts of the calyxes of $H$. sabdariffa which contain composite of anthocyanins. One of the biggest challenges ahead the human being is to replace the fossil fuel with renewable energy sources, while keeping pace with worldwide thirst for energy because of increasing population and rising demand from developing countries (Wang et al., 2010; Adenike et al., 2013), like Nigeria. This challenge has to be answered with a low-cost solution using abundantly available raw materials. Sun is an obvious source of clean and cheap energy, already used by nature to sustain almost all life on Earth (Grätzel, 2004; Bisquert et al., 2006). The dye-sensitized solar cell (DSSC) provides a technically and economically credible alternative concept to present day junction photovoltaic devices (Bisquert et al., 2004; Andre et al., 2006). In contrast to the conventional silicon systems, where the semiconductor assumes both the task of light absorption and charge carrier transport, the two functions are separated here. Light is absorbed by a sensitizer, which is anchored to the surface of a wide band gap oxide semiconductor: $\mathrm{TiO}_{2}$ was used. Charge separation takes place at the interface via photo-induced electron injection from the dye into the conduction band of the solid (Pooman \& Mehran, 2007). Transition metal coordination compounds (ruthenium polypyridyl complexes) have been used as the effective sensitizers, due to their intense charge- transfer absorption in the whole visible range and highly efficient metal-to-ligand charge transfer (Kelly \& Meyer, 2001; Grätzel, 2004). However ruthenium polypyridyl complexes have a heavy metal, which is undesirable from the environmental point of view (Brouillard et al., 2003; Cheng et al., 2011). Moreover, the process to synthesize the complexes is complicated and costly (Kay \& Grätzel, 2002; Boyo et al., 2012). The availability and low cost of the natural dyes made them better candidates to be used for the same purpose with an acceptable efficiency. The ability of this molecule to convert the light into electricity and to induce redox reactions is very interesting to be implemented in artificial systems (Duthie et al., 2000; Hwan et al., 2011).

\section{Materials and Methods}

The experimental studies for this work involved the extraction and purification of anthocyanins compounds in the plant materials, structural elucidation of the samples using spectrometry methods Ultra-violet (UV), Fourier transformed infra-red (FT-IR) and Gas chromatography coupled with Flame ionization detector (GC-FID), and photoelectrochemical studies i.e the fabrication and testing of dyesensitized solar cells using the crude and purified extracts of Hibiscus sabdariffa as the sensitizers.

Extraction and purification of anthocyanins compounds in plant materials

Plant material and sample preparation: dried calyxes of $H$. sabdariffa were purchased from Igbonno market, Osogbo, Nigeria. The samples were air dried under shade for ten days at room temperature. They were pulverized mechanically with the aid of liquidizer. Extraction of the sample was done using solvent system that comprised of distilled water, methanol and $1 \mathrm{M} \mathrm{HNO}_{3}$ in ratio 10 : 9: 1 respectively.

\section{Extraction and purification of the anthocyanin}

Modified methods of Takeda et al. (1994) which involve the use of a mixture of formic acid, ethanol, and distilled water (1:10:9) was employed. 
The samples were completely submerged in the solvent system and then covered in air tight glass bottle. Extraction was allowed to proceed for $24 \mathrm{~h}$. The extract was decanted and the solvent reduced by evaporation in water bath at $50 \pm 5{ }^{\circ} \mathrm{C}$ to obtain concentrated extract. The concentrated or dried extracts were stored in dark bottles at room temperature. About $7.32 \mathrm{~g}$ of dried extract of $\mathrm{H}$. sabdariffa extract (HSE) was obtained from the 50 $g$ of the calyxes (sample) extracted. Anthocyanin purification was done using the method of Ajiboye et al. (2011). The filtered extract was transferred into a separatory funnel and "washed" three times with equal volumes of ethylacetate to remove flavones. The third volume of the ethylacetate that was added and the extract were mixed thoroughly in the separatory funnel and left overnight. The ethylacetate-free layer, containing the partially purified anthocyanin, was obtained (Ajiboye et al., 2011). Then, $50 \mathrm{~mL}$ of the ethylacetate-free extract and $50 \mathrm{~mL}$ of $0.5 \%$ neutral lead acetate solution were mixed and kept in the refrigerator at $4^{\circ} \mathrm{C}$ for $48 \mathrm{~h}$ to ensure complete precipitation of anthocyanin. After $48 \mathrm{~h}$, blue supernatant was found and part of it was discarded. The precipitate was re-suspended in the remaining supernatant and transferred into test tubes, and was centrifuged at 5,000 rpm for 5 minutes. A blue supernatant and a dark precipitate (anthocyanidin) were obtained, and the supernatant was discarded. About $5 \mathrm{~mL}$ of $0.5 \%$ solution of sulfuric acid was added to the precipitate to remove lead as lead sulfate $\left(\mathrm{PbSO}_{4}\right)$, and the precipitate was simultaneously re-solubilized to give a red solution. The mixture was filtered to remove the $\mathrm{PbSO}_{4}$ and the filtrate. The filtrate was concentrated in a water bath at $50 \pm 5{ }^{\circ} \mathrm{C}$ to obtain the purified anthocyanin, which was stored in a dark plastic bottle in a refrigerator until use. About $2.61 \mathrm{~g}$ of the purified $H$. sabdariffa (HSP) sample was obtained from $50 \mathrm{~g}$.

Structural elucidation of the samples using UV, FTIR and GC-FID.

\section{Absorption spectroscopy}

UV-visible absorbance spectra of $H$. sabdariffa anthocyanin as well as the purified HSE and HSP respectively were scanned at 300 $-1,000 \mathrm{~nm}$ with a PerkinElmer UV-visible spectrometer (Lambda EZ201; PerkinElmer, Waltham, Massachusetts, USA).

Fourier transform infrared (FT-IR)

All experiments were performed under high vacuum (10 mbar) conditions using Fourier Transform infrared spectroscopy (FT-IR) over the $4000-350 \mathrm{~cm}^{-1}$ spectra range at $500 \mathrm{~cm}^{-1}$ resolution.

\section{Gas Chromatography coupled with Flame Ionization Detector (GC-FID)}

Qualitative and quantitative analyses of the six common anthocyanins were determined using gas chromatography coupled with Flame Ionization Detector (GC-FID) HP6890 powered with HP chem. Station Rev. A.09.01 [1206] software.

Photoelectrochemical Studies Preparation and deposition of titanium dioxide $\left(\mathrm{TiO}_{2}\right)$ film

Titanium dioxide $\left(\mathrm{TiO}_{2}\right)$ film was prepared by the incremental addition of $20 \mathrm{~mL}$ of $1.0 \mathrm{M} \mathrm{HNO}_{3}$ solution to $12 \mathrm{~g}$ of colloidal $\mathrm{TiO}_{2}$ powder (obtained from Degussa P25 $\mathrm{TiO}_{2}, 3500$ Embassy Parkway, Akron, $\mathrm{OH}, 44333, \mathrm{USA}$ ) in a mortar and pestle. The mixture was ground on each addition of the $1 \mathrm{~mL}$ acid solution until when the previously mixed and pulverized powder has produced a uniform and lumpfree paste (Boyo et al., 2013; Braun, 2006)

Glass plates coated with a conductive layer of fluorine doped $\mathrm{SnO}_{2}$ (obtained from Hartford Glass Co. Inc., P.O. Box 613, Hartford City, IN 47348, USA, Fax 765-348-5435) was cut into regular pieces $(2.5 \mathrm{~cm}$ by $2.5 \mathrm{~cm})$. A volt-ohm meter was used to check the conductive side of the glass. Four pieces of adhesive tape were applied to the face (edge) of the conductive glass plate in order to mask a 1-2 mm strip at three of the four edges, and a 4-5 mm strip was masked on the fourth side. The tape was extended from the edge of the glass to the table at a 450 angle to secure the glass. The tape formed $40-$ $50 \mu \mathrm{m}$ deep mold or channel into which the $\mathrm{TiO}_{2}$ solution flown and masked strip edge of the conductive glass was used as an avenue to establish electrical contact. Three drops of the water-based $\mathrm{TiO}_{2}$ solution was placed uniformly on the plate 
(approximately $5 \mu$ per $\mathrm{cm}^{2}$ ) then a glass stirring rod was rolled over the plate to spread and distributed the material. The film was then allowed to dry in air for $1 \mathrm{~min}$. The tape was carefully removed and the film was annealed and sintered in hot air stream (furnace) at $450{ }^{\circ} \mathrm{C}$ for $30 \mathrm{~min}$. The $\mathrm{TiO}_{2}$ coated conductive glass was allowed to slowly cool to room temperature. The resulting 7-10 $\mu \mathrm{m}$ thick $\mathrm{TiO}_{2}$ film has a porous (Close et al., 2003), sponge-like structure that enhances both the light absorption and electron collection efficiency in a similar way as the thylakoid membrane found in green plants (Jordheim et al., 2006; Kalaignan, 2006)

\section{Staining of the titanium dioxide with the dye}

$0.1 \mathrm{~g}$ each of the concentrated samples was dissolved in $5 \mathrm{~mL}$ of distilled deionized water, filtered and used as dye solution (Lee, 2002)

$\mathrm{TiO}_{2}$ coated glass plate was soaked (facing the dye solution) for $10 \mathrm{~min}$ in each of the various types of anthocyanin extracts, until the white $\mathrm{TiO}_{2}$ paste could not be seen upon viewing the stained film from either side of the supporting glass plate.

\section{Carbon coating the counter electrode}

While the $\mathrm{TiO}_{2}$ electrode was being stained in the anthocyanin solution, the counter electrode was made from another $(2.5 \mathrm{~cm}$ by $2.5 \mathrm{~cm}$ ) piece of conductive $\mathrm{SnO}_{2}$ coated glass. A graphite (carbon) rod was used to apply a light carbon film to the entire conductive side of the plate and the thin carbon layer served as a catalyst for the tri-iodide to iodide regeneration reaction, no masking tape was applied on the counter electrode, and thus the whole surface was catalyst coated. The carbon-coated counter electrode was annealed (heated and allowed to cool, to prevent internal stress) at $450{ }^{\circ} \mathrm{C}$ for about 5 minutes (Boyo et al., 2012). The counter electrode was carefully washed with ethanol and gently blotted dry with tissue paper before the device was assembled.

\section{Assembling the solar cell device andmeasurement of the electrical output characteristics}

The anthocyanin-stained $\mathrm{TiO}_{2}$ electrode was carefully removed rinsed with ethanol and gently blotted dry with tissue paper. The dried electrode was then quickly placed on the table such that the film side was faced up, and the catalyst-coated counter electrode was placed on the top so that conductive side of the counter electrode faces the $\mathrm{TiO}_{2}$. The two opposing glass plates were offset so that it was covered by the counter electrode, and the $4 \mathrm{~mm}$ strip of glass not coated by $\mathrm{TiO}_{2}$ was exposed. The two exposed sides of the device served as the contact points for the negative and positive electrodes through which electricity was extracted to test the cell. Two binder clips were used to gently hold the plates together at the other edges. Iodide electrolyte solution is $0.5 \mathrm{M}$ potassium iodide mixed with $0.05 \mathrm{M}$ iodine in water-free ethylene glycol. Two drops of the iodide/iodine electrolyte solution was then placed at the edges of the plates and the two binder clips were alternately opened and closed while the clips were in place. The liquid was drawn into the space between the electrodes by capillary action, and was seen to wet the stained $\mathrm{TiO}_{2}$ film (Boyo et al., 2012). The completed solar cell/light detector was taken for indoor measurements, the cell was illuminated by a 50 W (GE 12V) Tungsten Halogen lamp equipped with integral parabolic reflector and UV and IR blocking filter. The indoor light sources were calibrated by adjusting the light intensity or distance from the cell to the light source so that the maximum current values are identical to the outdoor measurements. The full current-voltage (I-V) curves were measured using a $1000 \Omega$ potentiometer as a variable load. Point by point current and voltage data was gathered at each incremental resistance value and plotted on graph paper. If a cell dries out, another drop of electrolyte was added to the edges of the plates to revive it.

\section{Measurement of the performance of the solar cells}

The four quantities; current density $\left(J_{s c}\right)$, open circuit voltage $\left(V_{o c}\right)$, fill factor $(F F)$ and the efficiency (n) were used to characterize the performance of the solar cells. These properties were measured under standard lighting conditions, which implies Air Mass 1.5 spectrum, light flux of $1000 \mathrm{~W} / \mathrm{m}^{2}$ and temperature of $25^{\circ} \mathrm{C}$. The four important quantities are measured are open circuit 
voltage $\left(V_{o c}\right)$, short circuit current $\left(I_{s c}\right)$, fill factor (FF) and efficiency ( $\eta$ )

$\mathrm{FF}=\frac{\mathrm{Jm}_{\mathrm{m}} \mathrm{V}_{\mathrm{m}}}{\mathrm{J}_{\mathrm{sc}} \mathrm{V}_{\mathrm{oc}}} \quad 1$

$\eta=\frac{P_{m}}{P_{s}} \quad 2$

The maximum power density occurs somewhere between $V=0$ (short circuit) and $V=V_{o c}$ (open circuit) at a voltage $V_{m}$. The corresponding current density is called $J_{m}$, and thus the maximum power density is $P_{m}=J_{m} V_{m}$. In these studies $P_{s}$ used was 50W throughout.

\section{Results and Discussion}

Spectroscopic data and spectra U-V spectra:
The U-V spectra of the extracts and the purified samples are presented in figures 1 to 2 and table 1 for the crude extract of $H$. sabdariffa (HSE) and purified extract of $H$. sabdariffa (HSP) respectively. The samples were scanned between $350-1000 \mathrm{~nm}$. There were significant difference in the absorbance and wavelengths of the HSE and HSP; the former has peaks with absorbance of 1.096 at $330 \mathrm{~nm}$ and 0.211 at $540 \mathrm{~nm}$, and a valley with absorbance of 0.116 at $450 \mathrm{~nm}$ and the latter, on the other hand has peaks with absorbance of 0.211 at $335 \mathrm{~nm}$ and 0.334 at $540 \mathrm{~nm}$, and a valley with absorbance of 0.077 at $400 \mathrm{~nm}$. There were shifts in the wavelengths of one peak (around $330-350$ $\mathrm{nm}$ ) and the valley, with a characteristic decrease in the absorbance of the peak and the valley. The absorbance at $540 \mathrm{~nm}$ has no shift in the two samples but an increase in the absorbance of HSP.

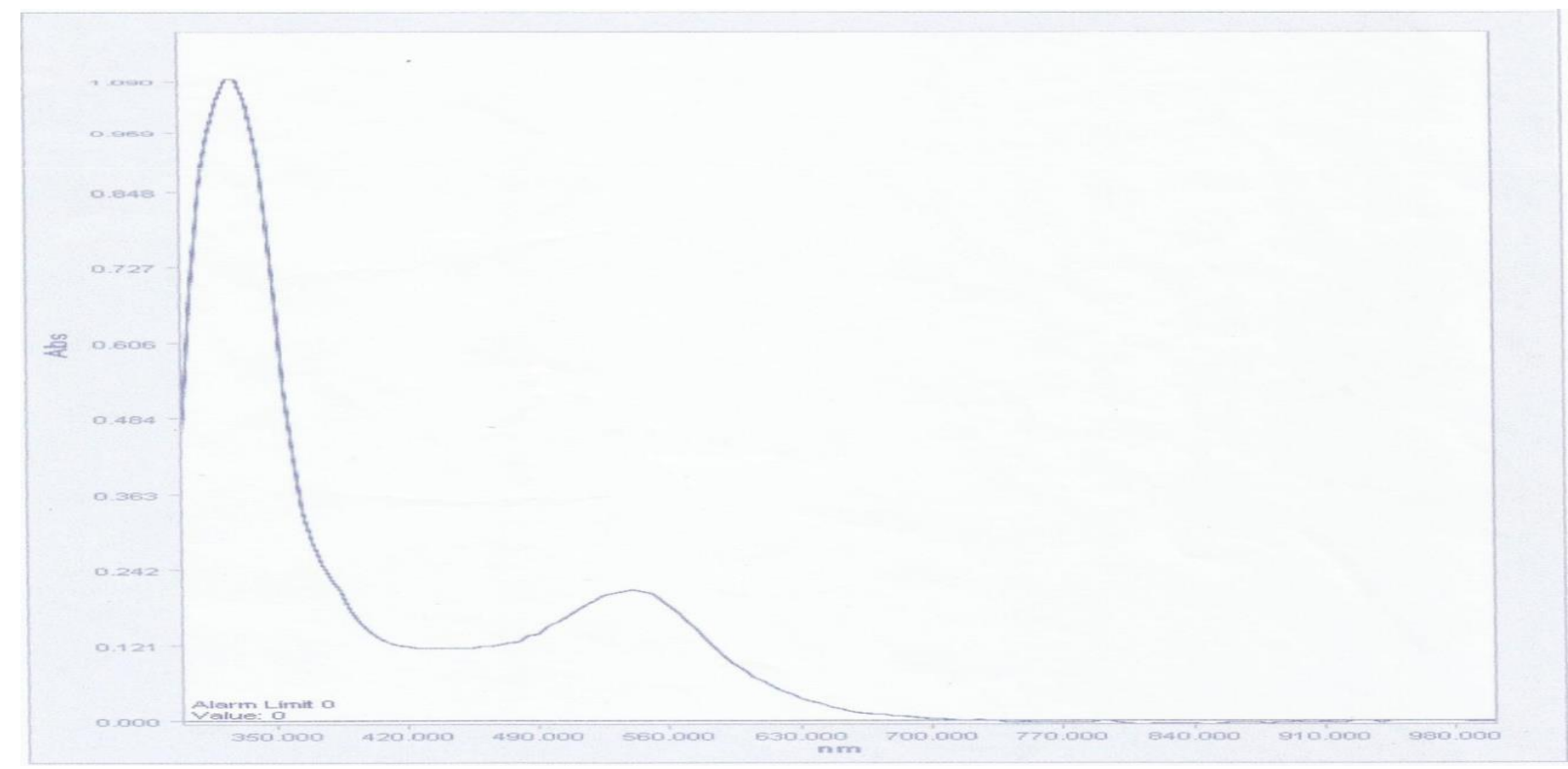

Figure 1: Absorption spectra of the crude extract of $H$. sabdariffa 
Fountain Journal of Natural and Applied Sciences: 2016; 5(1): 25 - 37

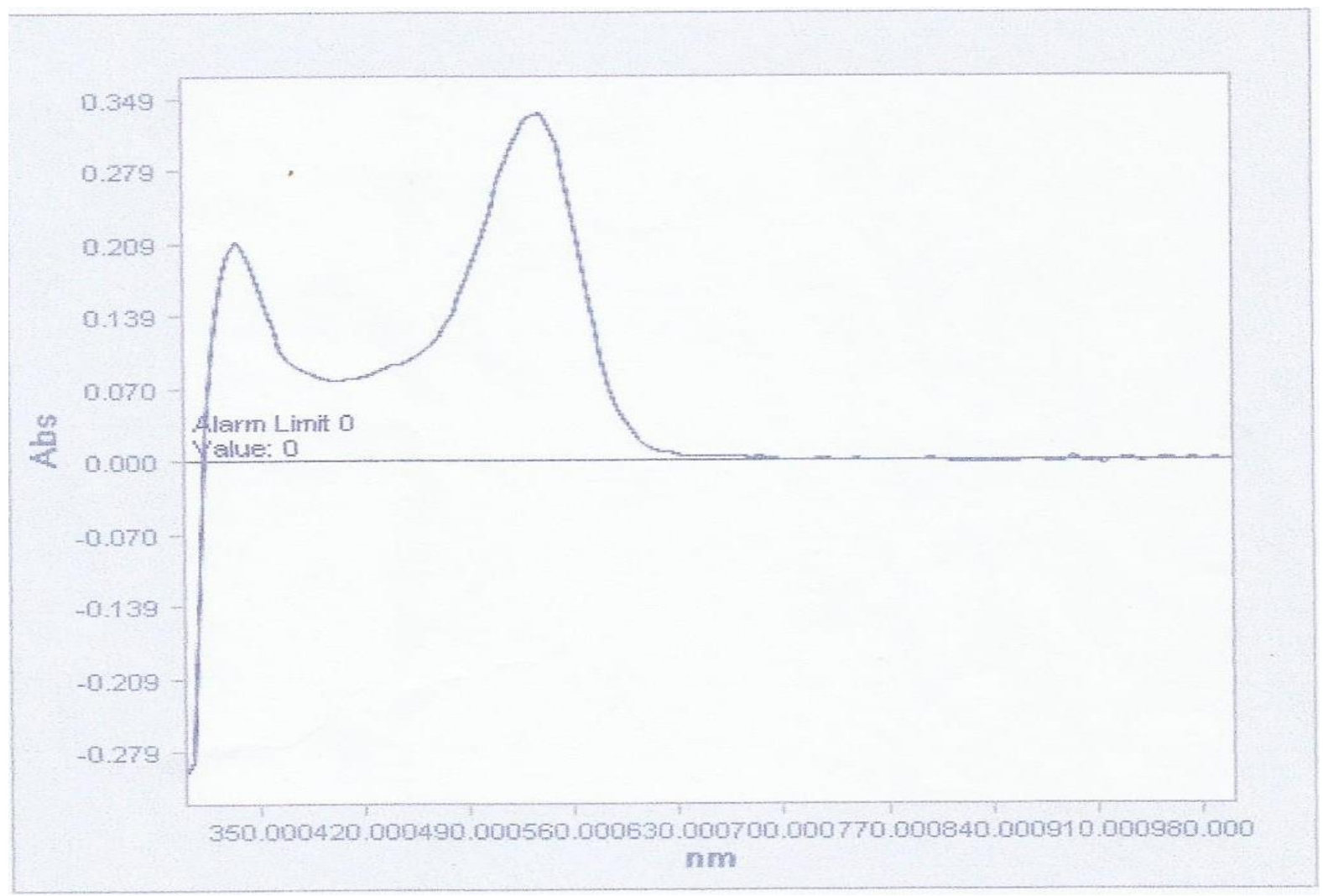

Figure 2: Absorption spectra of the purified extract of $H$. sabdariffa

Table 1: Summary of the U-V absorption peaks of HSE and HSP

\begin{tabular}{cccc}
\hline Sample & Absorbance & Wavelength (nm) & Nature of Absorbance \\
\hline HSE & 1.096 & 330 & Peak \\
& 0.211 & 540 & Peak \\
& 0.116 & 450 & Valley \\
\hline HSP & 0.211 & 335 & Peak \\
& 0.334 & 540 & Peak \\
& 0.077 & 400 & Valley
\end{tabular}

HSE = crude extract of $H$. sabdariffa.; $H S P=$ purified extract of $H$. sabdariffa 


\section{Fourier-transformed infrared spectra}

The spectra obtained for the FT-IR analyses of the HSE and HSP, are presented as Figs. 3 and
4 respectively and the Table 2 contained the summary spectra of the samples

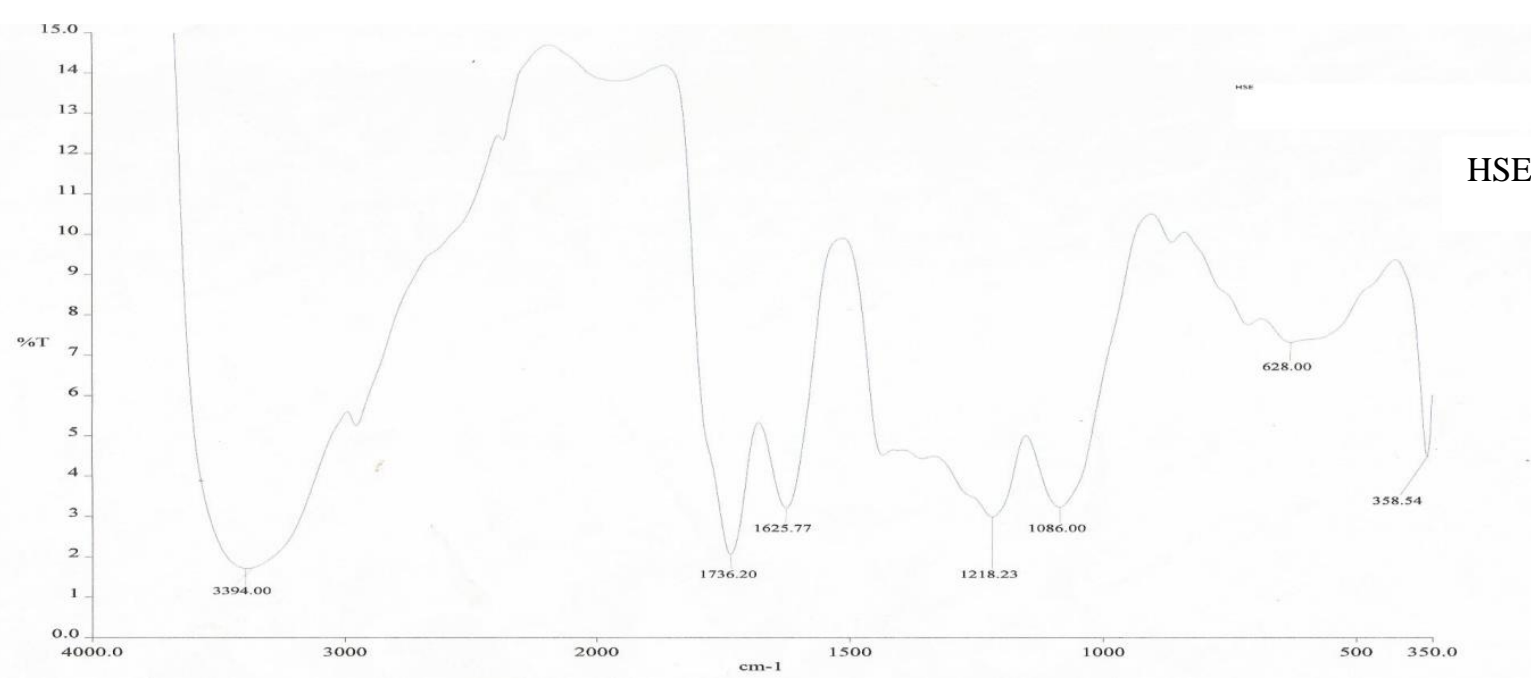

Figure 3: Fourier-transformed infrared spectra for the dye extract obtained from the calyxes of $H$. Sabdariffa

HSE = crude extract of $H$. sabdariffa

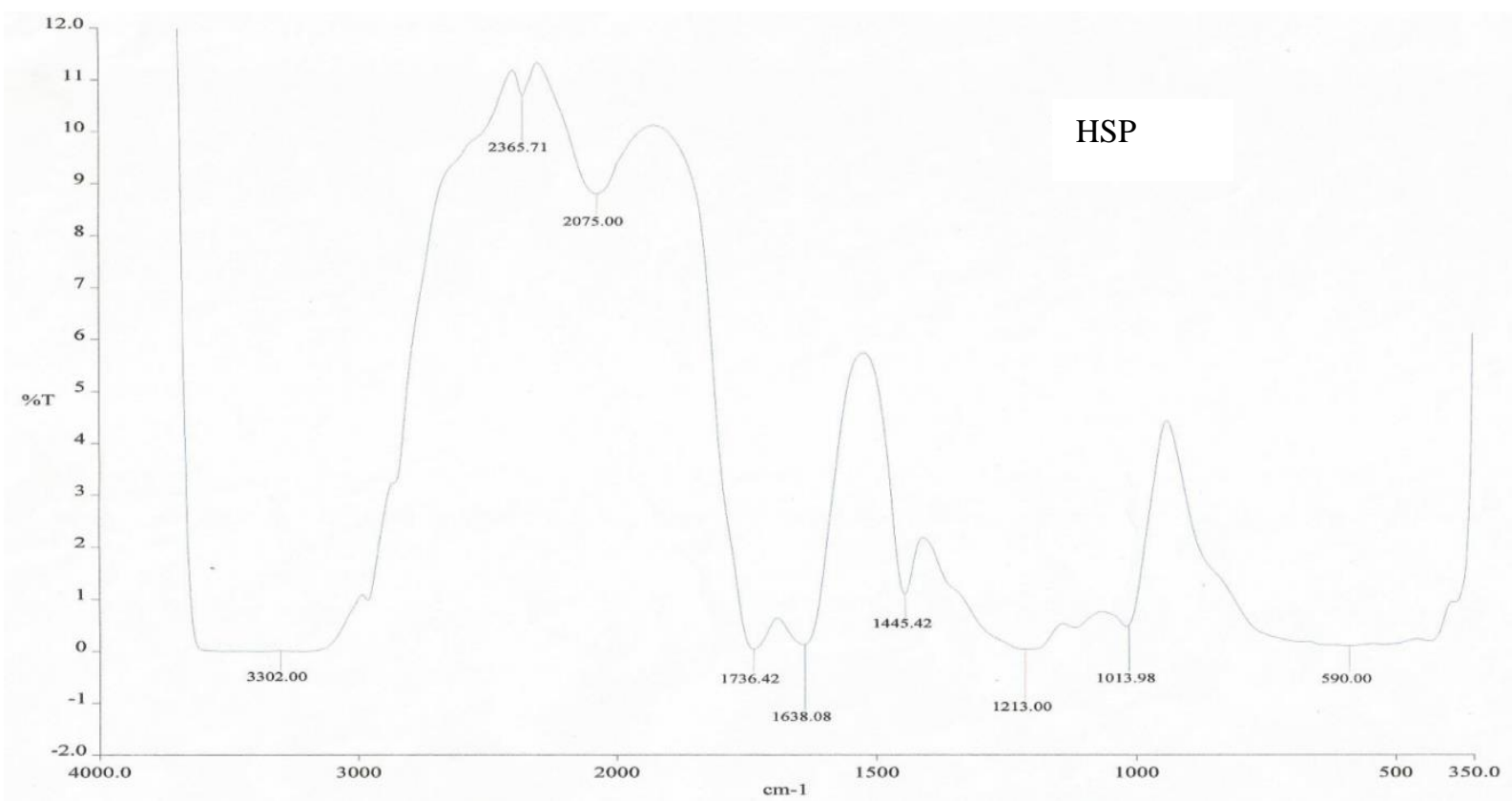

Figure 4: Fourier-transformed infrared spectra for the purified dye obtained from the calyxes of $H$. Sabdariffa HSP = purified extract of $H$. sabdariffa 
Table 2: Amount of anthocyanidins in the extracts and purified sample extracts

\begin{tabular}{clcc}
\hline $\mathrm{S} / \mathrm{N}$ & Anthocyanidin & HSE $(\mathrm{mg} / 100 \mathrm{~g})$ & $\mathrm{HSP}(\mathrm{mg} / 100 \mathrm{~g})$ \\
\hline 1 & Pelargonidin (Pg) & 4.148 & 2.250 \\
2 & Delphinidin (Dp) & 535.313 & 563.365 \\
3 & Cyanidin (Cy) & 72.700 & 43.817 \\
4 & Petunidin (Pt) & 1.826 & 0.837 \\
5 & Peonidin (Pn) & 1.223 & 0.121 \\
6 & Malvidin (Mv) & 1.217 & 0.034 \\
7 & Total & 616.426 & 610.423
\end{tabular}

HSE = crude extract of $H$. sabdariffa. HSP = purified extract of $H$. sabdariffa. The amount of HSE and HSP were expressed in mg per $100 \mathrm{~g}$ of the sample

The spectra of the HSE and HSP were similar with characteristic absorption of:

i. Hydroxyl (OH alcohol: $\left.3650-3200 \mathrm{~cm}^{-1}\right)$; although that of the HSP was broader

ii. Carboxyl ( $\left.C=0 ; 1780-1650 \mathrm{~cm}^{-1}\right)$

iii. Aliphatic $C-C$ double bond $(C=C ; 1680$ $1600 \mathrm{~cm}^{-1}$ )

iv. Aromatic $C-C$ double bond (benzene; 1600 $\left.\& \sim 1500-1430 \mathrm{~cm}^{-1}\right)$

v. Carbonyl (C-O; $\left.1230-1020 \mathrm{~cm}^{-1}\right)$

Apart from these two other absorbances were found on the spectra of the HSP, these were $2365 \mathrm{~cm}^{-1}$ and $2075 \mathrm{~cm}^{-1}$.

However, the spectra of the purified samples have bathochromic (red) (Bloor \& Falshaw, 2000; Braun, 2006) shifts on the hydroxyl group and hypsochromic (blue) shifts on the benzene ring (Doris et al., 2000; Forsen et al., 2003).

\section{Gas chromatography-flame ionization detector (GC-FID) chromatograms and spectra data.}

The GC-FID chromatograms and analyses of the anthocyanins in the HSE and HSP as presented in figures 5 to 8 and table 3 showed the amount of the anthocyanins in $\mathrm{mg}$ per $100 \mathrm{~g}$ of the sample. The chromatograms revealed the presence of the six common anthocyanidins and the spectra data showed the amount of the anthocyanidins in mg per $100 \mathrm{~g}$ of the sample. The results showed that delphinidin was abundant; $92.291 \%$ in HSP, followed by cyanidin up to about $11.794 \%$ in HSE. It was observed that the quantities of the delphinidin increased with purity of the extract, while the amount of others decreased with purity.

\section{Photoelectrochemical studies}

The results obtained for the four quantities; current density $\left(J_{s c}\right)$, open circuit voltage $\left(V_{o c}\right)$, fills factor (FF) and the efficiency (n), are presented as Table 3. Figure 9 shows a typical current-voltage curve for anthocyanin sensitized solar cell and Figure 10 shows the current-voltage curves for the crude and purified extracts of the $H$. sabdariffa. The photovoltaic performance of the extracts and purified extracts of the samples applied as sensitizers in DSCCS, it is evident from these data that the purified samples have higher fill factor and efficiency than the extract. However, the general performance of the samples (extracts and purified) were low. 


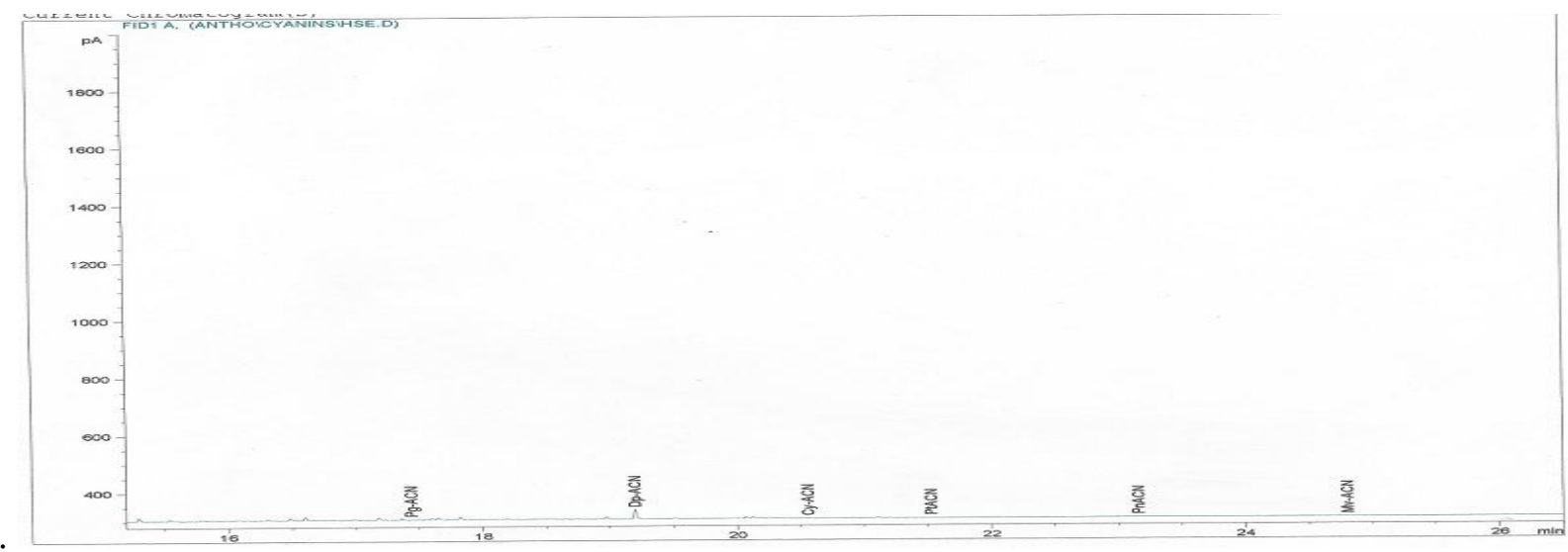

Figure 5: Gas chromatography-flame ionization detector chromatogram of dye extract obtained from $\mathrm{H}$. sabdariffa ANTHOCYANINS ANALYSIS

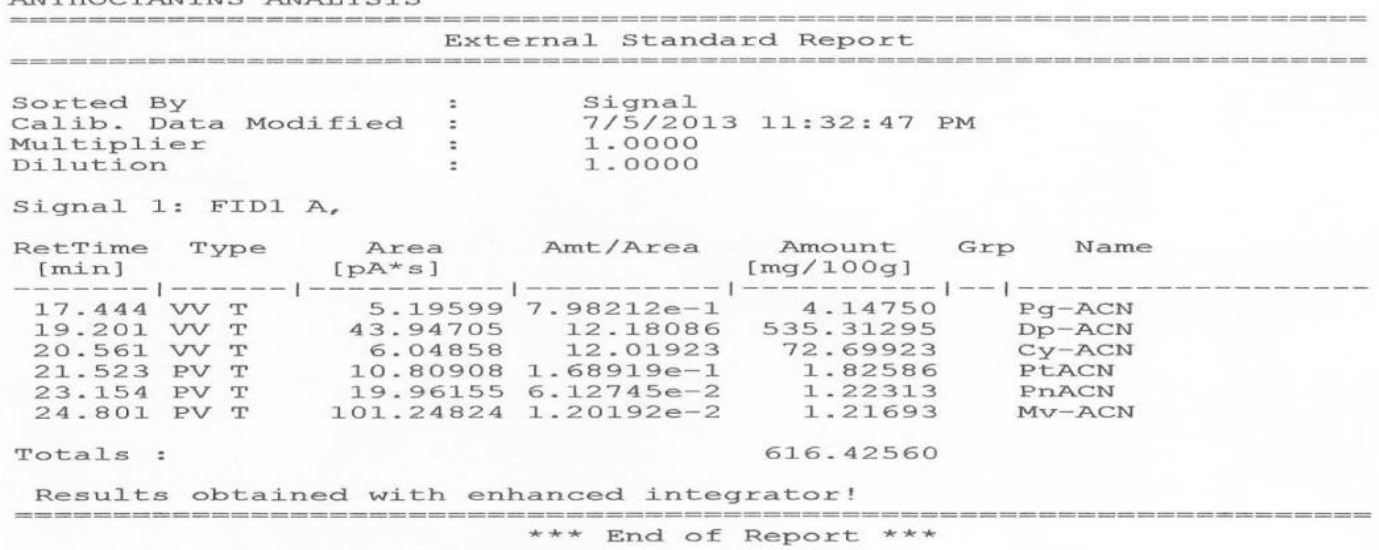

Figure 6: Gas chromatography-flame ionization detector spectra data of analysis of anthocyanins in the dye extract obtained from $H$. sabdariffa

$\mathrm{Pg}=$ Pelargonidin, $\mathrm{Dp}=$ Delphinidin, $\mathrm{Cy}=$ Cyanidin, $\mathrm{Pt}=$ Petunidin, $\mathrm{Pn}=$ Peonidin, $M v=$ Malvidin, $A C N=$ Anthocyanidin. RetTime $=$ Retention Time; $A m t /$ Area $=$ Amount of sample per unit Area; $m g=$ Milligram; $g=g r a m ; G r p=G r o u p$

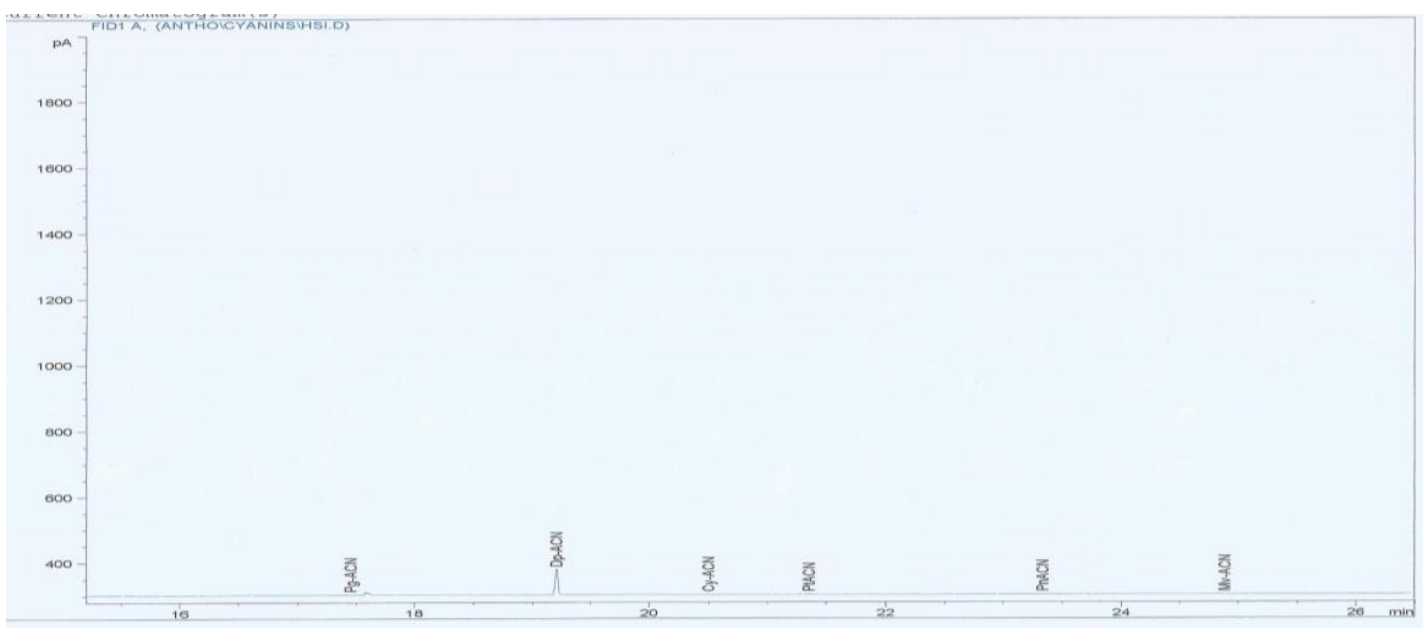

Figure 7: Gas chromatography-flame ionization detector chromatogram of purified dye extract obtained from $H$. sabdariffa

$P g=$ Pelargonidin, $D p=$ Delphinidin, $C y=C y a n i d i n, P t=P e t u n i d i n, P n=P e o n i d i n, M v=$ Malvidin, $A C N=A n t h o c y a n i d i n$ 


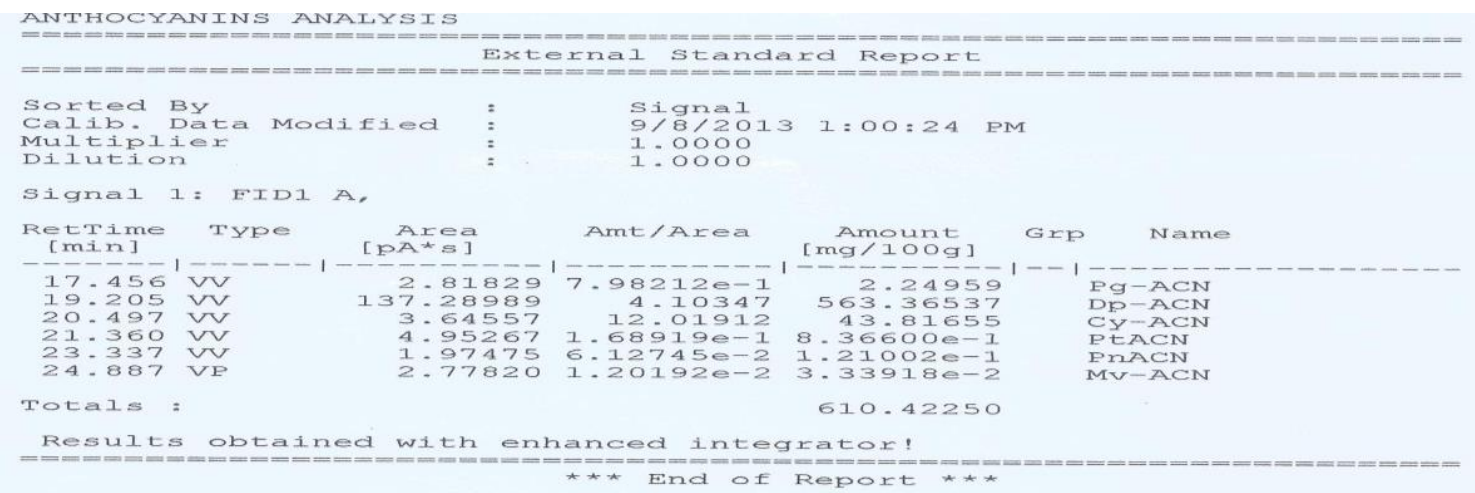

Figure 8: Gas chromatography-flame ionization detector spectra data of analysis of anthocyanins in the purified dye extract obtained from $H$. sabdariffa

$\mathrm{Pg}=$ Pelargonidin, $\mathrm{Dp}=$ Delphinidin, $\mathrm{Cy}=$ Cyanidin, $\mathrm{Pt}=$ Petunidin, $\mathrm{Pn}=$ Peonidin, $M v=$ Malvidin, $A C N=$ Anthocyanidin. RetTime $=$ Retention Time; $A m+/$ Area $=$ Amount of sample per unit Area; $m g=$ Milligram; $g=$ gram; Grp= Group.

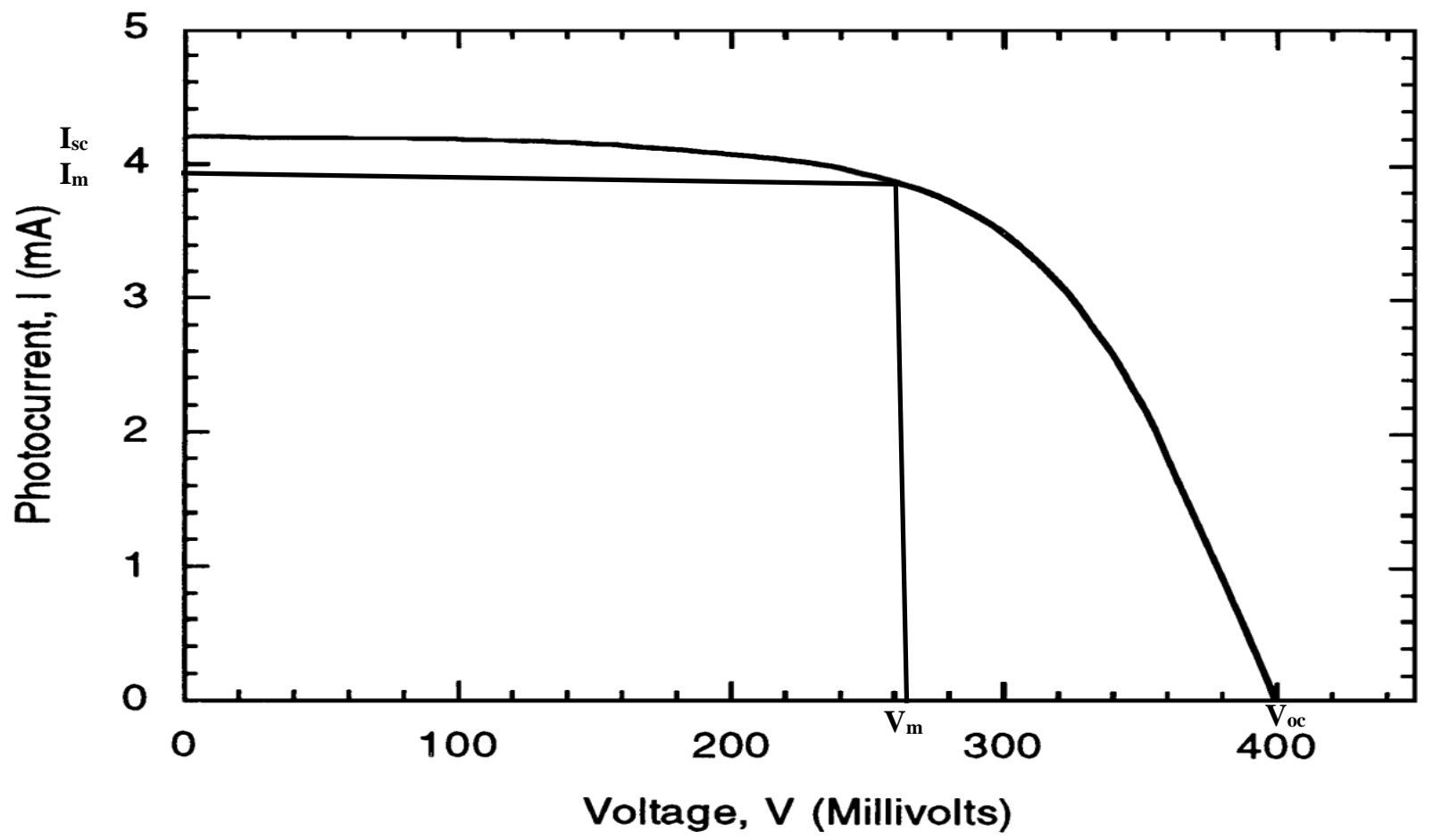

Figure 9: Typical current-voltage curve for anthocyanin sensitized solar cell. $\left(\right.$ Area $\left.=4 \mathrm{~cm}^{2}\right)$.

$I_{s c}=$ Short circuit current; $I_{m}=$ Maximum short circuit current; $V_{o c}=$ Open circuit voltage, $J_{s c}=$ Short circuit current density; $J_{\text {max }}=$ Maximum Short circuit current density; $F F=$ fill factor. 
Table 3: Photovoltaic performance of the extracts and purified extracts of the samples

\begin{tabular}{lllllllll}
\hline Sample & $\begin{array}{l}I_{s c} \\
(m A)\end{array}$ & $\begin{array}{l}J_{s c} \\
\left(m A / \mathrm{cm}^{2}\right)\end{array}$ & $\begin{array}{l}V_{o c} \\
(\mathrm{mV})\end{array}$ & $\begin{array}{l}I_{\max } \\
(\mathrm{mA})\end{array}$ & $\begin{array}{l}J_{\max } \\
(\mathrm{mA} / \mathrm{cm} 2)\end{array}$ & $\begin{array}{l}V_{\max } \\
(\mathrm{mV})\end{array}$ & $F F$ & $\begin{array}{l}\eta \\
(\%)\end{array}$ \\
HSE & 0.048 & 0.0120 & 4.830 & 0.014 & 0.0035 & 4.2 & 0.254 & 0.1176 \\
HSP & 0.035 & 0.0088 & 29.000 & 0.024 & 0.006 & 13.43 & 0.347 & 0.6446 \\
\hline
\end{tabular}

$I_{s c}=$ Short circuit current; $I_{\max }=$ Maximum short circuit current; $V_{o c}=$ Open circuit voltage, $J_{s c}=$ Short circuit current density; $J_{\max }=$ Maximum Short circuit current density; $F F=$ fill factor; $V_{\max }=$ Maximum Open circuit voltage; $n=$ overall efficiency. $H S E=$ crude extract of $H$. sabdariffa. HSP = purified extract of $H$. sabdariffa

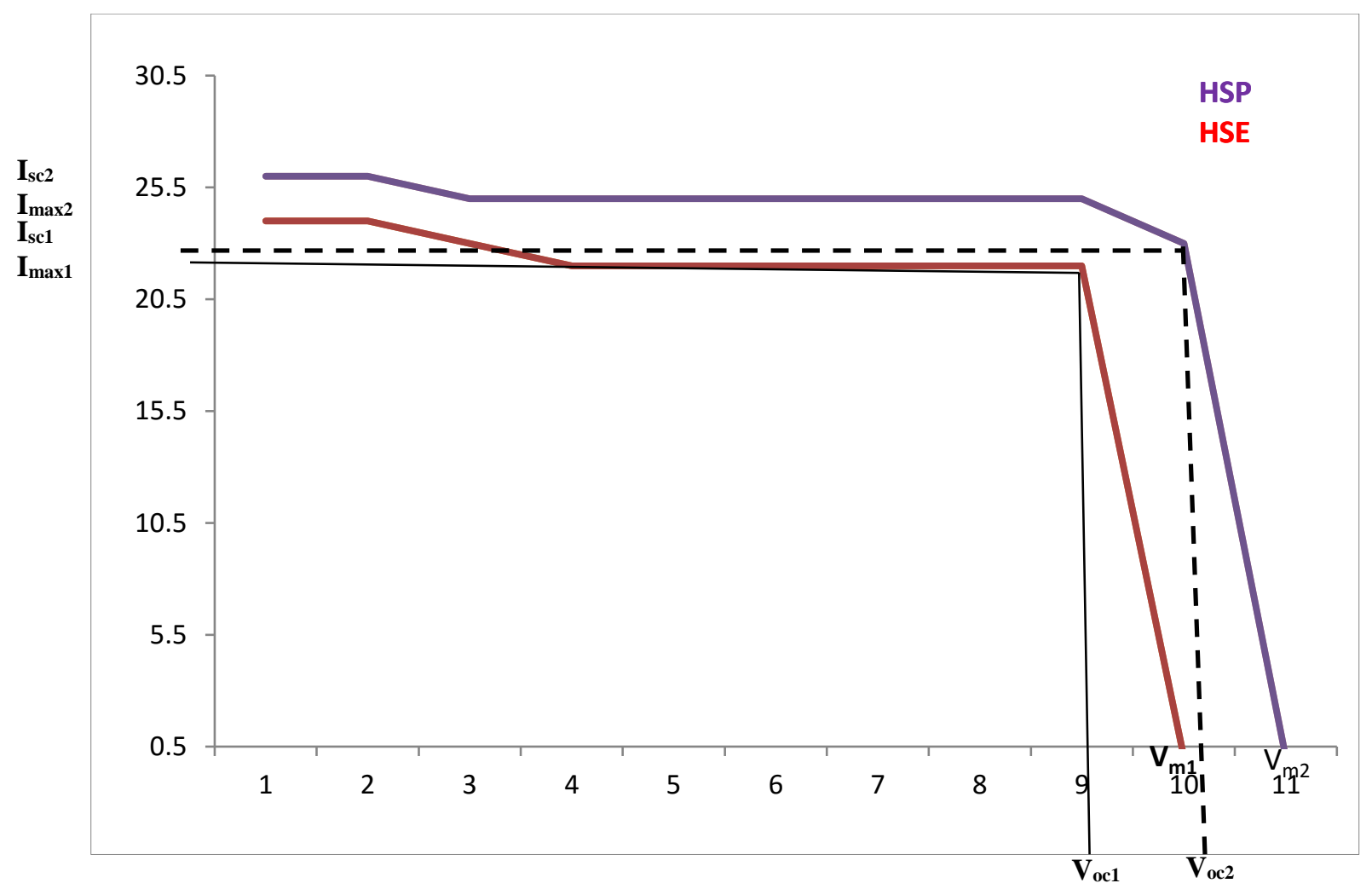

Figure 10: Current-voltage curve of solar cells fabricated using crude and purified extracts of $H$. sabdariffa as sensitizers

$I_{s c 1}=$ Short circuit current for HSE; $I_{s c 2}=$ Short circuit current for HSP; $I_{m 1}=$ Maximum short circuit current for HSE; $I_{m 2}=$ Maximum short circuit current for HSP; $V_{o c 1}=$ Open circuit voltage for HSE; $V_{o c 2}=$ Open circuit voltage for $H S P ; V_{m 1}=$ Maximum open circuit voltage for HSE; vm2 = Maximum open circuit voltage for HSP; HSE = crude extract of $H$. sabdariffa. HSP = purified extract of $H$. sabdariffa

\section{Conclusion}

In conclusion we reported the analysis of six common anthocyanins in the extract obtained from the calyxes of $H$. sabdariffa, with delphinidin being the most abundant and increased in amount as the purity of the extract is increased, and have prepared dye-sensitized solar cells using the crude and purified extracts (HSE and HSP respectively) obtained from the calyxes of Hibiscus sabdariffa. The dyes strongly absorb visible light between 330 $\mathrm{nm}$ and $540 \mathrm{~nm}$ and maximum absorption of HSE is about 1.096 a.u and 0.334 a.u for HSP. Despite strong light absorption, the cell efficiencies are low, with the best efficiencies of $0.645 \%$ for HSP- 
sensitized $\mathrm{TiO}_{2}$ cell. The low efficiencies are related to low injection efficiencies $(\mathrm{H}-\mathrm{Martinez}$ et al., 2012), indicating that the overlap of the dye excited states and the metal oxide conduction band (Nilsing, 2005). The dye regeneration kinetics and the dye excited state lifetime are not optimal; which could be as a result of the inhibitory effects of the composite anthocyanin molecules in the extract molecules.

\section{References}

Adenike, B., Okafor, P., Ibrahim, A., Oluwole, S. and Boyo, H. (2013). Application of Hibiscus Sabdariffa and leaves of Azardirachta Indica calyxes as sensitizers in Dyesensitized solar cells. International Journal of Engineering Research and Development. 8 (12) $38-42$

Ajiboye, T.O. A., Salawu, N. A., Yakubu, M. T., Oladiji, A. T., Akanji, M. and Okogun, J. I. (2011). Antioxidant and drug detoxification potentials of Hibiscus sabdariffa anthocyanin extract. Drug and Chemical Toxicology, 34(2): 109-115

Andre, S. P and Neyde, Y. M. I. (2006) Blue sensitizers for solar cells: Natural dyes from Calafate and Jaboticaba. Solar Energy Materials \& Solar Cells 90: 19361944

Bisquert J., Cahen, D., Hodes, G. Rühle, S. and Zaban, A. (2004). Physical Chemical Principles of Photovoltaic Conversion with Nanoparticulate, Mesoporous DyeSensitized Solar Cells. Journal of Physical Chemistry B. 108: 8106-8119.

Bisquert, J., Palomares, E. and Quiñones, C. (2006). Effect of Energy Disorder in Interfacial Kinetics of Dye-Sensitized Solar Cells with Organic Hole Transport Material.

The Journal of Physical Chemistry B.110: 19406-19411.

Bloor S.J, and Falshaw, R. (2000). Covalently linked anthocyanin-flavonol pigments from blue Agapanthus flowers. Phytochemistry. 53: 575-584.
Boyo, A. O., Boyo, H. O., Abdulsalami, I. O., and Adeola, S. (2012). Dye sensitized nanocrystalline titania solar cell using laali stem bark (Lawsonia inermis). Transnational Journal of Science and Technology, 2 (4): 60-72.

Boyo, A. O., Okafor P., Abdulsalami, I. O., Oluwole S., and Boyo, H. O., (2013). Application of Hibiscus sabdariffa and leaves of Azardirachta indica calyxes as sensitizers in Dye-sensitized solar cells. International Journal of Engineering Research and Development. 8 (12): 38-42.

Braun, R. D. (2006). Introduction to Instrumental Analysis: Infrared Spectroscopy, Pharmacology Book Syndicate. Hyderabad: 371-73.

Brouillard, R., Chassaing, S., and Fougerousse A. (2003). Why are grape/fresh wine anthocyanins so simple and why is it that red wine color lasts so long? Phytochemistry, 64:1179-1182.

Chen M.C., Liaw, D.J., Huang, C.Y., Wu, H.Y., Tai N, $Y$. (2011) Improving the efficiency of organic solar cell with a novel amphipolar polymer to form ternary cascade structure. Solar Energy Materials and Solar cells. 95, 26212627.

Close, D.C. and Beadle, C.L. (2003). The ecophysiology of foliar anthocyanin. Botanica Reviews, 69: 149-156.

Doris, V., Raimund, P. and Redinger, J. (2000). Ab initio study of atomic $\mathrm{Cl}$ adsorption on stoichiometric and reduced rutile $\mathrm{TiO}_{2}$ (110) surfaces. Surface Science. 4:369-373.

Duthie, G.G., Duthie, S.J., and Kyle, J.A.M. (2000). Plant polyphenols in cancer and heart disease: implications as nutritional antioxidants. Nutrition Resource Reviews 13: 79-88.

Fossen, T. and Andersen, Ø.M. (2003). Anthocyanins from red onion, Allium cepa, with novel aglycone. Phytochemistry. 62: 1217.

Fossen, T., Rayyan, S. and Andersen, Ø. M. (2004). Dimericanthocyanins from strawberry (Fragariaananassa) consisting of 
pelargonidin 3-glucoside covalently linked to four flavan-3-ols. Phytochemistry. 65: 1421-1430.

Grätzel, M. (2004). Conversion of sunlight to electric power by nanocrystalline dyesensitized solar cells. Journal of Photochemistry and Photobiology A: Chemistry. 164: 3-14.

Harborne, J.B. and Williams, C.A. (2000). Advances in flavonoid research since 1992 , Phytochemistry. 55: 481-493.

Hernández-Martínez .A.R., Estevez. M., Vargas, S., Quintanilla, F. and R. Rodríguez. (2012). Natural pigment-based dye-sensitized solar cells. First international congress on instrumentation and Applied Sciences. 51: 38-47.

Hwan, K.K., Dong, H. L., Myung J. L., Hae, M.S., Bok, J. S., Kang, D.S., Mariachaiara, P., Chiara, A., Simona, F., Filippo, D.A., Nazeeruddin, Md., Grätzel M. (2011). Organic dyes incorporating low- band-gap chromophores based on p-extended benzothiadiazole for dye-sensitized solar cells. Dyes and pigments. 91: 192-198

Ibrahim O. A., Bello I. A., Semire B., Bolarinwa H. S. and Boyo A. (2016). Purity-performance relationship of anthocyanidins as sensitizer in dye-sensitized solar cells. International Journal of Physical Sciences. 11(8), 104-111.

Jordheim, M., Fossen, T. and Andersen, $\varnothing$. M. (2006). Characterization of hemiacetal forms of anthocyanidin 3-O- $\beta$ glycopyranosides. Journal of Agriculture and Food Chemistry. 54: 9340- 9346.

Kalaignan, Y. Kang (2006). Journal of Photochemistry and Photobiology C: Photochemistry Reviews. 7: 17-22.

Kay, A. and Grätzel, M. (2002). Dye-Sensitized CoreShell Nanocrystals: Improved Efficiency of mesoporous Tin Oxide Electrodes Coated with a thin layer of an Insulating Oxide. Chemistry of Materials. 14: 29 - 30.

Kelly, C. A. and Meyer G. J. (2001). Excited state processes at sensitized nanocrystalline thin film semiconductor interfaces. Coordination
Chemistry Reviews. 211: 295 - 304.

Kim, S. S., Yum, J.H. and Sung Y.E. (2003). Improved performance of a dye-sensitized solar cell using a $\mathrm{TiO}_{2} / \mathrm{ZnO} /$ Eosin $\mathrm{Y}$ electrode. Solar Energy Materials \& Solar Cells. 79: 495 $-507$

Lee, H. S. (2002). Characterization of major anthocyanins and the color of red-fleshed Budd blood orange (Citrus sinensis). 50: 1243-1246.

Lundqvist, M. J., Nilsing, M., Persson, P. and S. Lunell. (2006). Spacer and anchor effects on the electronic coupling in Ruthenium bisterpyridine dye-sensitized $\mathrm{TiO}_{2}$ nanocrystals studied by DFT. International Journal of Quantum Chemistry. 106: 3214.

Middleton, E. Jr., Kandaswami, $C$., and Theoharides, T.C. (2000). The effects of plant flavonoids on mammalian cells: implications for inflammation, heart disease, and cancer. Pharmacology Reviews. 52: 673-682.

Nilsing, M., Lunell, S., Persson, P. and L. Ojamäe. (2005). Phosphonic acid adsorption at the $\mathrm{TiO}_{2}$ anatase (101) surface investigated by periodic hybrid HF-DFT computations. Surface Science. 582: 44-49

Pooman, S. and Mehra R. M. (2007). Effect of electrolytes on the photovoltaic performance of a hybrid dye ZnO solar cell. Solar Energy Materials \& Solar Cells. 91: 518-524.

Simmonds, M. S. J. (2003). Flavonoid-insect interactions: recent advances in our knowledge, Phytochemistry, 64, 21.

Takeda, K., Sato, S., Kobayashi, H., Kanaitsuka, V., Uene, M., Kinoshita, T., (1994). The anthocyanin responsible for purplish blue flower colour of Aconitum chinense. Phytochemistry 36:613-616.

Wang, P., Zakeeruddin, S., and Grätzel, M. (2010). High Efficiency solid-state sensitized heterojunction photovoltaic device. Nano Today, 5: 169-174. 